SHORT COMMUNICATION

\title{
LUMBAR DRAINS CAN AFFECT CSF BIOMARKER LEVELS
}

\author{
Claudia L Craven MRCS MSc [1] claudia.craven@gmail.com \\ Miles D Chapman PhD [5] miles.chapman@uclh.nhs.uk \\ Linda D'Antona MBBS BSc [1] linda.D’Antona@uclh.nhs.uk \\ Simon D Thompson MSc [1] simon.thompson3@nhs.net \\ Henrik Zetterberg PhD MD [2,3] henrik.zetterberg@clinchem.gu.se \\ Laurence D Watkins FRCS (Neuro.Surg.) MD [1] laurence.watkins@uclh.nhs.uk \\ Ahmed K Toma FRCS (Neuro.Surg.) MD (Res.) [1] ahmedtoma@nhs.net
}

[1] Victor Horsley Department of Neurosurgery, National Hospital for Neurology and Neurosurgery, Queen Square, London, WC1N 3BG, UK

[2] Department of Molecular Neuroscience, UCL Institute of Neurology, Queen Square, London, WC1N 3BG, UK

[3] Department of Psychiatry and Neurochemistry, Institute of Neuroscience and Physiology, the Sahlgrenska Academy at the University of Gothenburg, S-431 80 Mölndal, Sweden

[4] UK Dementia Research Institute at UCL, London, WC1N 3BG, UK

[5] Department of Neuroimmunology, National Hospital for Neurology and Neurosurgery, Queen Square, London, WC1N 3BG, UK

Corresponding author: Claudia L Craven

Postal Address: Victor Horsley Department of Neurosurgery, National Hospital for Neurology and Neurosurgery, Queen Square, London, WC1N 3BG, UK.

Email: claudia.craven@gmail.com

Phone: +447454336888

Disclosure: Portions of this work were presented in abstract form at the Hydrocephalus 2016 International Society for Hydrocephalus and Cerebrospinal Fluid Disorders Conference, Cartagena, Colombia, October 2016. L D Watkins has received honoraria from and served on advisory boards for Medtronic, Bbraun and Codman. 


\section{ABSTRACT}

We investigate the effect of both silver-lined (Silverline $\AA$, Spiegelberg, GMBH \& Co.) and barium-impregnanted (EDM, Medtronic) lumbar catheters on concentrations of AB1-42 and Ttau in CSF.

CSF was collected from individuals of unknown disease via lumbar puncture (LP). CSF was thawed at $21^{\circ} \mathrm{C} \mathrm{CSF}$ and and centrifuged for 5 minutes. A volume of $800 \mathrm{uL}$ was injected into (1) $2 \mathrm{ml}$ Sarsted aliquot (control), (2) barium-lined LD $80 \mathrm{~cm}$ (3) silver-lined LD $80 \mathrm{~cm}$. CSF was collected through an LD over 3 different time periods: 30 seconds, 1 minute and 5 minutes (drain clamped before allowing CSF to drain). CSF was then collected into $2 \mathrm{ml}$ Sarsted aliquots. Each test was repeated three times per tube type, and per time protocol. Mean CSF concentrations $(\mathrm{pg} / \mathrm{ml})$ were corrected for total protein.

A maxium reduction of $A \beta 1-42 \mathrm{pg} / \mathrm{ml}$ of $21.8 \%$ and $21.5 \%$ for barium-impregnated and silverlined catheters respectively, compared to control CSF that did not pass through a catheter. If the CSF was imediately sampled from the drain, the reduction was less, being $12.4 \%$ and $5.00 \%$ for barium-impregnated and silver-lined catheters respectively, however this reduction was still signfiicant. T-tau levels were not significantly altered.

Adsorption of $A \beta$ peptides to the luminal surface of lumbar drains needs accounting for when interpreting concentrations, to prevent misleading diganosis or inaccurate results.

KEYWORDS: idiopathic normal pressure hydrocephalus (INPH); Alzheimer's disease (AD), Ttau; AB1-42; cerebrospinal fluid (CSF); neurodegenerative markers 


\section{INTRODUCTION}

The proteins Tau and A $1-42$ are two conventionally measured cerebrospinal fluid (CSF) biomarkers that can assist with the diagnosis of neurodegenerative disease. In Alzheimer's disease a high CSF total-tau (T-tau) concentration reflects neuroaxonal degeneration/injury and low CSF A $1-42$ correlates with senile plaque pathology [1,2].

There is evidence that these markers could be useful in the diagnosis of NPH. In NPH, lumbar CSF levels of Tau and Aß1-42 are typically low or low/normal (respectively), and could potentially discriminate from Alzheimer's disease, in addition to being a putative prognostic marker for shunt responsiveness [3-6].

When measured in the context of investigating NPH, CSF is usually sampled from the lumbar drain, in-situ as part of the diagnostic protocol $[7,8]$. Increasingly lumbar drains are also being used to research rostrocaudal gradients of neurodegenerative markers, or within a study protocol method to obtain longitudinal biomarker results (to avoid multiple lumbar punctures) [9-11].

CSF transfer between collection tubes can reduce the overall concentration of $A \beta 1-42$ by $25 \%$, due to adsorption to the ionic surfaces [12]. It is unclear if the same effect is observed when CSF is sampled from lumbar drain.

We investigate the effect of both silver-lined (Silverline®, Spiegelberg, GMBH \& Co.) and barium-impregnanted (EDM, Medtronic) lumbar catheters, vs. lumbar puncture on concentrations of $A \beta 1-42$ and T-tau in CSF.

\section{METHOD}

\section{Collection of CSF}

CSF was collected from two anonymous individuals of unknown disease via lumbar puncture (LP). CSF sample collection and storage methods were all in accordance with the consensus guidelines for CSF biobanking [13]. 


\section{Lumbar drain testing}

CSF was thawed at $21^{\circ} \mathrm{C}$ and centrifuged for 5 minutes. A volume of $800 \mathrm{uL}$ was injected into (1) $2 \mathrm{ml}$ Sarsted aliquot (control), (2) barium-lined LD $80 \mathrm{~cm}$ (3) silver-lined LD $80 \mathrm{~cm}$. CSF was collected through a LD over 3 different time periods: 30 seconds, 1 minute and 5 minutes (drain clamped before allowing CSF to drain). CSF was then collected into $2 \mathrm{ml}$ aliquots (Sarstedt, Numbrecht, Germany). Each test was repeated three times per tube type, and per time protocol.

\section{Electrochemiluminescent immunoassay analysis}

Samples underwent biochemical and enzyme-linked immunosorbent (ELISA) analysis to measure concentrations of T-tau (INNOTEST hTAU ELISA, Fujirebio, Ghent), A $\beta-42$ (INNOTEST $\beta$-amyloid (1-42), Fujirebio, Ghent). Total protein (TP) was measured as a control. A technician prospectively recorded levels of $T$-tau and $A \beta-42$ and was blinded to the tube type and dwell time.

Longitudinal stability in the measurements was ascertained using an elaborate programme of internal quality control (QC) samples. The laboratory also takes part in the Alzheimer's Association external QC programme for CSF biomarkers. Intra- and inter-assay coefficients of variation were $12-15 \%$ for $A \beta 1-42$ and $3-12 \%$ for T-tau.

\section{Statistical analysis}

Mean CSF concentrations (pg/ml) were corrected for TP. Measurement of uncertainly (MU) in T-tau and $\mathrm{AB} 1-42$ is $3-47$ and $9-17 \mathrm{pg} / \mathrm{ml}$ respectively. ANOVA (Geisser-Greenhouse correction) determined significance.

\section{RESULTS}

A Percentage reduction in $A \beta 1-42 \mathrm{pg} / \mathrm{ml}$ for barium-impregnated catheters and silver-lined catheters are $9.3 \%$ (range $7.4-11.1 \%$, taking MU corrections into account) and $20.5 \%$ (range 11.3-22.3) respectively, when CSF had dwelled in the catheter tube for 5 minutes (table 1). This reduction was significant in the silver-line tubing group. T-tau levels were not significantly altered.

Table 1. Five min. CSF dwell time and neurogenertaive marker concentrations (sample 1) 


\begin{tabular}{|l|l|l|l|l|l|}
\hline & Control & $\begin{array}{l}\text { Barium LD } \\
\text { mean }(n=3)\end{array}$ & $\begin{array}{l}\text { Silver LD } \\
\text { mean }(n=3)\end{array}$ & $\begin{array}{l}\text {-value (after MU } \\
\text { correction) }\end{array}$ & \\
\hline T-tau $\mathrm{pg} / \mathrm{ml}$ & 638 & 631 & 714 & 0.222 & \\
\hline A $1-42 \mathrm{pg} / \mathrm{ml}$ & 1737 & 1575 & 1381 & 0.003 & \\
\hline
\end{tabular}

A significant percentage reduction in A $\beta 1-42 \mathrm{pg} / \mathrm{ml}$ was observed for both bariumimpregnated catheters and silver-lined catheters, dropping by $21.8 \%$ (range 11.6-26.9\%) and $21.5 \%$ (range 11.8-30.1\%) respectively, when CSF had dwelled in the catheter tube for 1 minute (table 2). T-tau levels were not significantly altered.

Table 2. One min. CSF dwell time and neurogenertaive marker concentrations (sample 2)

\begin{tabular}{|l|l|l|l|l|l|}
\hline & Control & Barium LD & Silver LD & $\begin{array}{l}\text { p-value (after MU } \\
\text { correction) }\end{array}$ \\
\hline T-tau pg/ml & 385 & 317 & 376 & 0.003 & \\
\hline A $\beta 1-42 ~ p g / m l$ & 922 & 721 & 724 & 0.001 \\
\hline
\end{tabular}

Although the percentage reduction in $A \beta$ peptide was less, there was still significant reduction in A $1-42 \mathrm{pg} / \mathrm{ml}$ for both barium-impregnated catheters and silver-lined catheters, dropping by $12.4 \%$ (range $8.68-16.1 \%$ ) and $5.00 \%(0.97-8.67 \%$ ) respectively, when CSF had been pulled straight through the lumbar catheter tube in over 30-50 seconds (table 3). T-tau levels were not significantly altered.

Table 3. Less than 1 min. CSF dwell time and neurogenertaive marker concentrations (sample 2)

\begin{tabular}{|l|l|l|l|l|l|}
\hline & Control & Barium LD & Silver LD & $\begin{array}{l}\text {-value (after MU } \\
\text { correction) }\end{array}$ & \\
\hline T-tau pg/ml & 385 & 305 & 361 & 0.999 & \\
\hline A 1 -42 pg/ml & 922 & 808 & 879 & 0.040 & \\
\hline
\end{tabular}

\section{DISCUSSION}

There are no publications demonstrating the clinical or research implications of analysing CSF samples for neurodegenerative proteins, when taken from a lumbar drain. We demonstrate that 
CSF taken from lumbar drains can have artificially low A $\beta 1-42$ concentrations (regardless of the drain being barium or silver lined).

CSF collection methods have been previosuly scrutinised regarding this issue. It has been found that aspiration of CSF (as opposed to drip collection) does not alter the levels of relevant proteins [14]. Furthermore, transfer at room temperature (and not on ice), and transfer times over 24 hours also do not significanlty alter the levels of Tau and Aß1-42 [15]. The use of manometers during collection can reduce $A \beta 1-38 / 40 / 42$ levels, but ultimately does not alter the ratio's measured [16]. A $\beta$ peptides are known to be 'sticky' and can be adsorbed to ionic surfaces of collection tubes, particularly during serial transfers [12].

With lumbar drain CSF concentrations of $A \beta 1-42$ being reduced by up to $20 \%$ there is potential for misdiagnosis of Alzheimer's disease. Furthermore, our findings have important implications for clinical research, where lumbar drains are thought to be a more patient friendly method of CSF collection when serial samples are needed. This adsorption of $A \beta$ peptides to the luminal surface of lumbar drains needs accounting for when interpreting concentrations, to prevent misleading diganosis or inaccurate results.

The effect A $A 1-42$ peptides adsorption is reduced when CSF is pulled through immediately (5\% reduction in barium lined lumbar drains). If a diagnosis of Alzheimer's rests upon the results, additional testing with a lumbar puncture would be prudent. We advocate taking the adsorption effect into account when writing clinical or research protocols involving lumbar drains and analysis of $A \beta$ peptide concentration results.

\section{RESEARCH IN CONTEXT}

1. Systematic review: There are no publications demonstrating the clinical or research implications of analysing CSF samples for neurodegenerative proteins, when taken from a lumbar drain.

2. Interpretation: We demonstrate that CSF taken from lumbar drains can have artificially low $A \beta 1-42$ concentrations.

3. Future directions: Both clinical and research protocols analysing CSF AB1-42 concentrations from lumbar drains should acknowledge this potential effect

\section{REFERENCES}


1. Blennow K. Cerebrospinal fluid protein biomarkers for Alzheimer's disease. NeuroRx 2004;1:213-225.

2. Graff-Radford NR. Alzheimer CSF biomarkers may be misleading in normal-pressure hydrocephalus. Neurology 2014;83:1573-1575.

3. Jeppsson $\mathrm{A}$, Zetterberg $\mathrm{H}$, Blennow $\mathrm{K}$ et al. Idiopathic normal-pressure hydrocephalus: pathophysiology and diagnosis by CSF biomarkers. Neurology 2013;80(15):1385-1392.

4. Jingami N, Asada-Utsugi M, Uemura K, et al. Idiopathic normal pressure hydrocephalus has a different cerebrospinal fluid biomarker profile from Alzheimer's disease. J Alzheimers Dis 2015;45:109-115.

5. Kapaki EN, Paraskevas GP, Tzerakis NG, et al. Cerebro- spinal fluid tau, phosphotau181 and beta-amyloid1- 42 in idiopathic normal pressure hydrocephalus: a discrimination from Alzheimer's disease. Eur J Neurol 2007;14:168-173. 5.

6. Craven $\mathrm{CL}$, Baudracco I, Zetterberg H, et al. The predictive value of T-tau and AB1-42 levels in idiopathic normal pressure hydrocephalus. Acta Neurochir (Wien) 2017;159(12):2293-300.

7. Mahr CV, Dengl M, Nestler U, et al. Idiopathic normal pressure hydrocephalus: diagnostic and predictive value of clinical testing, lumbar drainage, and CSF dynamics. J Neurosurg 2016;125(3):591-7.

8. Relkin $\mathrm{N}$, Marmarou $\mathrm{A}$, Klinge $\mathrm{P}$, et al. Diagnosing idiopathic normal-pressure hydrocephalus. Neurosurgery 2005;57(3 Suppl):S4-16; discussion ii-v.

9. Brandner $\mathrm{S}$, Thaler $\mathrm{C}$, Lelental $\mathrm{N}$, et al. Ventricular and lumbar cerebrospinal fluid concentrations of Alzheimer's disease biomarkers in patients with normal pressure hydrocephalus and posttraumatic hydrocephalus. J Alzheimers Dis 2014;41(4):105762.

10. Cicognola $C$, Chiasserini D, Eusebi $P$, et al. No diurnal variation of classical and candidate biomarkers of Alzheimer's disease in CSF. Mol Neurodegener 2016;11(1):65.

11. Tarnaris A, Toma AK, Chapman MD, et al. The longitudinal profile of CSF markers during external lumbar drainage. J Neurol Neurosurg Psychiatry 2009;80(10):1130-3.

12. Toombs J, Paterson RW, Schott JM, et al. Amyloid-beta 42 adsorption following serial tube transfer. Alzheimers Res Ther 2014;6(1):5.

13. Teunissen $\mathrm{CE}$, Tumani H, Bennett JL et al. Consensus Guidelines for CSF and Blood Biobanking for CNS Biomarker Studies. Mult Scler Int 2011:246412. 
14. Rembach A, Evered LA, Li QX, et al. Alzheimer's disease cerebrospinal fluid biomarkers are not influenced by gravity drip or aspiration extraction methodology. Alzheimers Res Ther 2015;7(1):71.

15. Paterson RW, Toombs J, Chapman MD, et al. Do cerebrospinal fluid transfer methods affect measured amyloid beta42, total tau, and phosphorylated tau in clinical practice? Alzheimers Dement (Amst) 2015;1(3):380-4.

16. Toombs J, Foiani MS, Paterson RW, et al. Effect of Spinal Manometers on Cerebrospinal Fluid Amyloid-beta Concentration. J Alzheimers Dis 2017;56(3):885-91. 